\title{
Isolamento de Enterobactérias em Alphitobius Diaperinus e na Cama de Aviários no Oeste do Estado do Paraná, Brasil
}

Isolation of Enteric and Litter Organisms from Alphitobius Diaperinus in Brooder Chickens Houses in West of Parana State, Brazil

\section{Autor(es) / Author(s)}

Chernaki-Leffer AM ${ }^{1}$
Biesdorf SM ${ }^{2}$
Almeida LM ${ }^{1}$
Leffer EVB
Vigne $F^{4}$
1-Programa de Pós- Graduação em Entomologia,
Depto. de Zoologia - UFPR, Curitiba
2-Centro de Diagnóstico Marcos Enrietti,
Campus I UFPR, Curitiba
3-Gerente Técnico de Avicultura- Schering-
Plough Coopers
4-M édico Veterinário- Cooperativa Agropecuária
Cascavel Ltda

\section{- Correspondência / Mail Address}

Lúcia M assutti de Almeida

Depto de Zoologia - UFPR

Caixa Postal 19020

81531-980 - Curitiba - PR - Brasil

E-mail: amcleffer@uol.com.br

\section{Unitermos / Keywords}

Alphitobius Diaperinus, enterobactérias, granjas avícolas

Alphitobius Diaperinus, enterobacteriacea, poultry brooder houses

\section{Observações / Notes}

Contribuição № 1358 do Depto. de Zoologia, Universidade Federal do Paraná.

Agradecimentos ao Sr. Jair Luiz Casarotto (Gerente de Produção Avícola) e Sra. Alzira T. Matsuda de Medeiros (Engenheira Química) da COOPAVEL - Cooperativa Agropecuária Cascavel Ltda, ao Centro de Diagnóstico Marcos Enrietti e ao $\mathrm{CNPq}$.

\section{RESUMO}

0 objetivo deste trabalho foi realizar 0 isolamento de bactérias da família Enterobacteriaceae em adultos de A. diaperinus, buscando uma correlação entre as bactérias presentes no inseto e na cama, em aviários para produção de frangos de corte no oeste do Paraná, Brasil. No primeiro experimento, insetos adultos foram coletados em 14 granjas. No segundo experimento, foram coletados insetos e material da cama de 12 diferentes aviários. Os adultos foram anestesiados com éter, macerados em solução salina e o material da cama colhido por "swab" de arrasto. O enriquecimento não seletivo foi feito com caldo $\mathrm{BHI}$ e o seletivo com Rappaport-Vassiliadis e Tetrationato. Os meios de cultivo para plaqueamento foram o ágar M acConkey, ágar Salmonella-Shigella e ágar verde-brilhante. As enterobactérias isoladas em adultos de $A$. diaperinus foram: Proteus Vulgaris, P. mirabilis, Escherichia Coli, Enterobacter spp., E. agglomerans, E. gergoviae, E. sakasakii, Citrobacter Diversus e Klebsiella Pneumoniae, enquanto que na cama foram encontrados Proteus Vulgaris, P. mirabilis, Escherichia Coli, Enterobacter Agglomerans. Não foram isoladas Salmonella spp. do inseto nem da cama e P. vulgaris foi a predominante. E. coli foi freqüente nas granjas, tanto na cama como nos insetos e contribuem na disseminação da colibacilose em aviários.

\section{ABSTRACT}

This study was conducted to determine bacterial species of Enterobacteriaceae in adults of lesser mealworm, A. diaperinus and make the correlation of the bacterial species in the insects and in the litter that infest poultry brooder houses in West of Parana State, Brazil. In the first experiment, the adults were collected in 14 poultry houses. In the second experiment the insects and the litter were collected in 12 poultry houses. The adults were anaesthetized with eter, macerated in sterile saline solution and the litter material was taken off by swab. The enrichment broth was plated on the BHI and in Rappaport-Vassiliadis and Tetrationate. The agar M acConkey, agar Salmonella-Shigella and agar brilliant green was used as plating media for isolating the enterobacteria. The enterobacteria isolated in adults of A. diaperinus were: Proteus Vulgaris, P. mirabilis, Escherichia Coli, Enterobacter spp., E. agglomerans, E. gergoviae, E. sakasakii, Citrobacter Diversus and Klebsiella Pneumoniae. In the litter were found Proteus Vulgaris, P. mirabilis, Escherichia Coli, Enterobacter Agglomerans. There was no Salmonella spp. found in the insect and the litter and P. vulgaris was predominant. E. coli was found in the poultry houses, in the litter and the insects and the bacteria are responsible for dissemination of colibacilose. 


\section{INTRODUÇÃO}

O Brasil é consolidado pela alta produtividade da atividade agropecuária, dentro da qual a avicultura vem se destacando no cenário internacional. Qualidade e baixos custos são fatores que colocam o Brasil como o 3 maior produtor e 2ㅇ maior exportador de frangos do mundo. 0 estado do Paraná é o maior produtor de frangos (18,6\% da produção nacional) e o oeste paranaense é responsável por $47 \%$ da produção do estado (1,13 milhão de aves/ dia).

Este crescimento tem estimulado práticas de manejo como o aumento do número de lotes sobre a mesma cama (devido à escassez da maravalha) e intervalos entre lotes algumas vezes reduzido ( 5 a 10 dias). Estes fatores parecem contribuir para 0 aumento populacional de Alphitobius Diaperinus, o cascudinho. Esse inseto foi encontrado infestando aviários em Indiana, Estados Unidos, desde 1950 (Gould \& M oses, 1951). Segundo Chernaki \& Almeida (2001), o ciclo total de $\mathrm{A}$. diaperinus à temperatura constante de $28^{\circ} \mathrm{C}$ é de 42,5 dias, o que indica que a cada lote introduzido na granja (o que ocorre a cada 50 dias, aproximadamente) pode ocorrer uma nova geração de insetos, podendo cada fêmea produzir acima de 2 mil ovos (Steelman, 1996).

Conforme Harris (1966), os estágios de larva e adulto alimentam-se de carne e órgãos internos de aves mortas ou moribundas. Esse hábito, somado ao contato direto do inseto com a cama das aves (rica em excrementos e restos de ração), faz desse coleóptero um possível veiculador de diversos patógenos, como o vírus da leucose aviária (Eidson et al. 1965; 1966); vírus da Doença de Gumboro (M cAllister et al. 1995); Coronavirus (Watson et al. 2000); bactérias como M icrococcus sp., Streptococcus sp., Corynebacterium sp., Bacillus Subtilis, Staphylococcus Aureus, Proteus M irabilis, P. vulgaris, Paracolobactrum Intermedium, Escherichia Coli, E. intermedia, E. freundii, Serratia M arcescens, KlebsiellaAerobacter, Pseudomonas Aeruginosa e Salmonella Saint Paul; fungos como Aspergillus Flavus, A. niger, A. repens, A. candidus, Penicillium sp. e Candida sp. (De las Casas et al., 1972) e protozoários como Eimeria (Steelman, 1996; Goodwin \& Waltman, 1996).

De las Casas et al. (1968) evidenciaram a capacidade de A. diaperinus em transmitir Escherichia Coli, podendo causar contaminação de alimentos para animais e humanos. Em 1970, Harein et al. isolaram de adultos de $A$. diaperinus 26 sorotipos patogênicos de E. coli. A bactéria também foi isolada da cama de aviários, embora a maior quantidade de sorotipos tenha sido isolada dos insetos. McAllister et al. (1996), estudando larvas e adultos do inseto, encontraram E. coli na superfície externa e interna de seus corpos. As fezes das larvas continham a bactéria por 6 dias e, nos adultos, por 10 dias. Porém, após a passagem de um estágio larval para outro, a bactéria não foi mais detectada nas fezes, indicando que não ocorre passagem transestadial.

Dentre as bactérias, as do gênero Salmonella apresentam maior importância na avicultura devido ao risco de contaminação alimentar em seres humanos. Essa bactéria já foi isolada de A. diaperinus e sua presença é rotineiramente verificada na cama dos aviários através de pesquisa bacteriológica. Conforme De las Casas et al. (1968), os adultos de A. diaperinus são capazes de veicular Salmonella Typhimurium. Harein et al. (1970) isolaram 5 espécies de Salmonella em adultos de A. diaperinus, identificadas como S. heidelberg, S. whorthington, S. san paul, S. thyphimurium var. copenhagen. M cAlllister et al. (1994) encontraram S. typhimurium em larvas e adultos de Alphitobius Diaperinus, na superfície e no interior do corpo. A bactéria foi isolada das fezes dos besouros por 28 dias após uma única exposição por 24 horas. Entretanto, Davies \& Wray (1995) não conseguiram isolar S. enteritidis de A. diaperinus, porém em swab de superfície de dois aviários, 22\% das amostras continham a bactéria. Harein et al. (1972) isolaram microorganismos da cama e de $A$. diaperinus; concluíram que a cama apresentou um maior número de bactérias quando comparadas às amostras de insetos. Os autores também encontraram Salmonella spp. na superfície da cama e nos insetos.

Este trabalho tem como objetivo o isolamento de bactérias da família Enterobacteriaceae em adultos de $A$. diaperinus, buscando também uma correlação entre as bactérias presentes no inseto e na cama, em aviários para produção de frangos de corte no oeste do Paraná, Brasil.

\section{MATERIAL E MÉTODOS}

\section{Experimento I}

Adultos de Alphitobius Diaperinus (Panzer, 1797) (Coleoptera: Tenebrionidae) foram coletados em 14 granjas avícolas do oeste do Paraná e submetidos à análise bacteriológica com objetivo de verificar a presença de enterobactérias. 


\section{Experimento II}

Na segunda etapa, foram feitas coletas de insetos e do material da cama de 12 aviários localizados na mesma região da etapa anterior, em sítios diferentes.

\section{Preparo dos Insetos}

Os insetos foram coletados em diversos locais das granjas, abaixo dos comedouros e acondicionados em potes plásticos providos de aeração. Após encaminhamento das amostras ao laboratório, os adultos foram separados do material da cama, anestesiados em éter e pesados. 0 macerado foi feito em condições assépticas, utilizando-se cubas e pistilos estéreis. No primeiro experimento, os adultos foram macerados em $10 \mathrm{~mL}$ de água destilada estéril e no segundo experimento, em $10 \mathrm{~mL}$ de solução salina estéril $0,85 \%$. 0 macerado em solução salina foi adotado nesta etapa conforme indicado nos trabalhos de De las Casas et al. (1968, 1972) e Harein et al. (1970, 1972).

\section{Swab de Arrasto}

Esta técnica é feita como rotina em aviários para detectar presença de Salmonella spp.

Inicialmente, foi preparado um meio de préenriquecimento em caldo não seletivo, que compreende uma solução de leite $1 \%$ (Leite Molico Nestlé S.A.) e Caldo Triptose Fosfato) esterilizados à $121^{\circ} \mathrm{C}$ por 15 minutos e conservados em frascos estéreis $(500 \mathrm{~mL})$ com tampa rosqueável.

Foram utilizados $200 \mathrm{~mL}$ por galpão. No momento da coleta, gazes com cordas esterilizadas ( 3 gazes por galpão) foram mergulhadas na solução e em seguida arrastadas por toda a área do aviário. Após feito o arrasto, as gazes foram novamente mergulhadas, mantidas fechadas nos vidros e conservadas em gelo reciclável. Seis horas antes do processamento das amostras no laboratório, os frascos foram retirados do gelo e mantidos em temperatura ambiente $\left( \pm 25^{\circ} \mathrm{C}\right)$.

As etapas bacteriológicas seguiram a metodologia empregada para o macerado, conforme Experimento II, porém as amostras de swab foram homogeneizadas e colhidas com pipetas estéreis.

\section{Etapas do Procedimento Bacteriológico}

Primeiro: Plaqueamento direto das amostras de macerado em meios de cultura seletivos- indicadores ágar MacConkey (MC), ágar verde brilhante (VB) e ágar Salmonella- Shigella (SS), incubados a $37^{\circ} \mathrm{C}$ por 24 horas (Experimento I).

Segundo: Inóculo das amostras em caldo de enriquecimento não seletivo Brain Heart Infusion (BHI), em caldo de enriquecimento seletivo Rappaport-Vassiliadis (RV) (Experimento I e II) e caldo Tetrationato (TT) (Experimento II). Foram utilizados $2 \mathrm{~g}$ de insetos em 20 $\mathrm{mL}$ de $\mathrm{BH}, 0,2 \mathrm{~g}$ em $20 \mathrm{~mL}$ de RV e $2 \mathrm{~g}$ em $20 \mathrm{~mL}$ de $T$.

Terceiro: Incubação dos caldos de enriquecimento a $37^{\circ}$ e $43^{\circ} \mathrm{C}$, por 18 a 24 horas, procedendo-se em seguida o plaqueamento nos meios seletivo-indicadores, com auxílio de alça níquel-cromo. As placas foram levadas à estufa por 18 a 24 horas a $37^{\circ} \mathrm{C}$ (Experimento I e II).

Quarto: Leitura das placas, onde foram selecionadas 2 ou 3 colônias pequenas e/ou médias, fermentadoras da lactose (incolores), com característica de Salmonella e também aquelas de coloração rosada e esverdeada.

Quinto: Identificação bioquímica preliminar: consistiu em repicar de cada uma das placas 2 a 3 colônias com as características anteriormente citadas em ágar TSI (Triple Sugar Iron) e LIA (Lisina Iron Agar), incubados a $37^{\circ} \mathrm{C}$ por 18 a 24 horas.

Sexto: Provas bioquímicas complementares: 0 crescimento bacteriano no TSI foi repicado para meios como o SIM (Sulphide Indol Motility), caldo uréia, vermelho de metila (VM), voges-Proskauer (VP) e citrato de Simmons.

Sétimo: Após 18 a 24 horas a $37^{\circ} \mathrm{C}$, os resultados foram comparados com base na tabela de diferenciação de Enterobacteriaceae (Quinn et al., 1994).

\section{RESULTADOS}

Não foi realizada contagem bacteriana em placas, sendo portanto uma análise estritamente qualitativa.

\section{Experimento I}

Foram isoladas dos insetos 9 espécies de bactérias: Proteus Vulgaris, P. mirabilis, Escherichia Coli, Enterobacter spp., E. agglomerans, E. gergoviae, E. sakasakii, Citrobacter Diversus e Klebsiella Pneumoniae.

Não foi isolada Salmonella spp. nas amostras de macerado de insetos.

Proteus Vulgaris foi encontrado em $71,4 \%$ das granjas. E. coli foi a segunda mais freqüente, isolada dos insetos em $42,8 \%$ das granjas.

P. mirabilis foi isolada em $28,5 \%$ das granjas, $E$. agglomerans em $21,4 \%$ e C. diversus em $14,2 \%$. Em 
menor quantidade $(7,1 \%)$, K. pneumoniae e demais espécies de Enterobacter.

\section{Experimento II}

Não foram isoladas Salmonella spp. dos insetos nem do material da cama colhido através de swab de arrasto. Proteus Vulgaris foi a bactéria mais predominante. As bactérias isoladas da cama nem sempre estavam presentes nos insetos, embora a diversidade tenha sido a mesma nas duas condições. Foi verificado também que a maior porcentagem de granjas afetadas teve contaminação bacteriana oriunda dos insetos (Tabela 1).

\section{DISCUSSÃO}

As bactérias isoladas neste estudo foram relatadas por vários autores americanos nas décadas de 70 e 80, não havendo até então registros deste tipo de pesquisa no Brasil. Dessa forma, a caracterização desse inseto como veiculador de bactérias entéricas torna este estudo bastante relevante para avicultura brasileira.

Concordando com os resultados deste trabalho, De las Casas et al. (1972) isolaram os gêneros Proteus e Klebsiella. Segundo Harrison \& Harrison (1986), K. pneumoniae é causadora da pneumonia de Friedländer's em humanos, entretanto não há relatos de que a doença seja uma zoonose. Os mesmos autores citam que o gênero Citrobacter, também isolado do inseto neste trabalho, provoca bacteremia após penetração na mucosa intestinal, podendo até causar a morte em aves jovens, sendo que, clinicamente, sinais de diarréia podem ser observados. Relataram ainda que os gêneros Enterobacter e Proteus são geralmente de baixa patogenicidade. Entretanto Morgan (1965) relata que bactérias gram-negativas como Proteus sp. podem ser patogênicas ou potencialmente patogênicas para animais de sangue quente, incluindo o homem.

0 isolamento de Escherichia Coli neste trabalho confere com os resultados de De las Casas et al. (1968, 1972), Harein et al. $(1970,1972)$ e McAllister et al. (1996). E. coli pode infectar aves causando uma doença conhecida como colibacilose. 0 agente causal é habitante normal do trato intestinal de mamíferos e aves, entretanto, algumas cepas podem causar a doença em aves imunodeprimidas. Neste estudo não foi verificado a patogenicidade dos isolados de E. coli.

Embora tenha sido buscado, o gênero Salmonella esteve ausente em todas as avaliações, o que confere com os resultados de Davies \& Wray (1995), que sugerem que Alphitobius Diaperinus possa ser relativamente resistente à colonização por esta bactéria, sendo a contaminação persistente do ambiente e de animais associados os maiores fatores de risco de infecção. Harein et al. $(1970,1972)$ isolaram espécies de Salmonella de A. diaperinus, representando $2,2 \%$ do total da população testada, mas acreditam que essa porcentagem pode ser significativamente maior e que as colônias podem ter sido contaminadas por Citrobacter spp. e Proteus spp., que produzem colônias semelhantes a Salmonella no ágar verde brilhante. Em 1972, citam ainda que 0 isolamento da bactéria ocorreu mais precocemente em insetos analisados individualmente que quando analisados em grupos, relatando também que $A$. diaperinus contribui significativamente na transmissão de microorganismos quando comparados com amostras de cama e pó em aviários. Conforme Nascimento et al. (2000), a presença de enterobactérias dificulta a ação dos caldos de enriquecimento (Tetrationato, p. ex.) sobre os microorganismos competidores. Todos estes fatores podem explicar a ausência de Salmonella nesta análise, se porventura as amostras analisadas estivessem contaminadas.

\section{CONCLUSÕES}

Pode-se concluir que os adultos de Alphitobius Diaperinus albergam bactérias diversas e, embora não tenham sido isoladas espécies de Salmonella, estas podem estar presentes, já que o inseto vive em um ambiente rico em matéria orgânica, em contato com as aves.

Os resultados indicam que $\mathrm{E}$. coli é bastante freqüente em granjas avícolas, tanto na cama, como no inseto, e que $A$. diaperinus contribui na disseminação dessa bactéria em aviários.

O material de cama analisado mostrou conter as mesmas bactérias presentes no inseto, porém em menor quantidade por granja avaliada.

Com isso, pode-se afirmar que o controle de A. diaperinus deve ser reforçado, bem como os cuidados com o manejo da cama de aviários, posto que ambos são fontes de disseminação de microorganismos aos frangos de corte. 
Tabela 1 - Bactérias isoladas em macerado de Alphitobius Diaperinus (Panzer) na cama e em ambos substratos, coletados em 12 granjas avícolas do oeste do Paraná.

\begin{tabular}{lccc} 
Bactérias & Macerado & Cama & Macerado e Cama \\
\hline Proteus Vulgaris & $11(83,3 \%)$ & $8(66,6 \%)$ & $9(75 \%)$ \\
\hline Proteus M irabilis & $6(50 \%)$ & $4(33,3 \%)$ & $2(16,6 \%)$ \\
\hline Escherichia Coli & $4(33,3 \%)$ & $4(33,3 \%)$ & $2(16,6 \%)$ \\
Enterobacter Agglomerans & $2(16,6 \%)$ & $1(8,3 \%)$ & $1(8,3 \%)$ \\
\hline
\end{tabular}

\section{REFERÊNCIAS BIBLIOGRÁFICAS}

Chernaki AM, Almeida LM. Exigências térmicas, período de desenvolvimento e sobrevivência de imaturos de Alphitobius diaperinus (Panzer) (Coleoptera: Tenebrionidae). Neotropical Entomology 2001; 30 (3): 365-8.

Davies RH, Wray C. Contribution of the lesser mealworm beetle (Alphitobius Diaperinus) to carriage of Salmonella Enteritidis in poultry. Veterinary Record 1995; 137: 407-8.

De las Casas E, Pomeroy BS, Harein PK. Infection and quantitative recovery of Salmonella Typhimurium and Escherichia Coli from within the lesser mealworm, Alphitobius Diaperinus (Panzer). Poultry Science 1968; 47(6): 1871-5.

De las Casas E, Harein PK, Pomeroy BS. Bacteria and fungi within the lesser mealworm collected from poultry brooder houses. Environmental Entomology 1972; 1(1): 27-30.

Eidson CS, Schmittle SC, Lal JB, Goode RB. The role of darkling beetle (Alphitobius diaperinus) in the transmission of acute leukosis in chickens. Poultry Science 1965; 44: 1366-1367.

Eidson CS, Schmittle SC, Goode RB, Lal JB. Induction of leukosis tumors with the beetle Alphitobius Diaperinus. American Journal Veterinary Research 1966; 27(119): 1053-7.

Goodwin M.A., Waltman WD. Transmission of Eimeria, Viruses, and bacteria to the chicks: darkling beetles (Alphitobius Diaperinus) as vectors of pathogens. Journal of Applied Poultry Research 1996; 5: 51-55.

Gould GE, Moses HE. Lesser mealworm infestation in a broiler house. Journal of Economic Entomology 1951; 44: 265.

Harein PK, De las Casas E, Pomeroy BS, York M D. Salmonella spp. and sorotypes of Escherichia coli isolated from the lesser mealworm collected in poultry brooder houses. Journal of Economic Entomology 1970; 63(1): 80-2.

Harein PK, De las Casas E, Larsen CT, Pomeroy, BS. Microbial relationship between the lesser mealworm and its associated environment in a turkey brooder house. Environmental Entomology 1972; 1(2): 189-193.
Harris F. Observations on the lesser mealw orm, Alphitobius Diaperinus (Panz.). Journal of the Georgia Entomologic Society 1966; 1(1): 17-8.

Harrison GJ, Harrison LR. Clinical Avian Medicine and Surgery. W.B. Saunders Company. Philadelphia 1986; 717p.

M callister JC, Steelman CD, Skeeles JK. Reservoir Competence of the Lesser Mealworm (Coleoptera: Tenebrionidae) for Salmonella Typhimurium (Eubacteriales: Enterobacteriaceae). Journal of M edical Entomology 1994; 31(3): 369-372.

M callister JC, Steelman CD, Newberry LA, Skeeles JK. Isolation of Bursal Disease virus from the lesser mealworm, Alphitobius diaperinus (Panzer) Poultry Science 1995; 74: 45-9.

M callister JC, Steelman CD, Skeeles JK, Newberry LA, Gbur EE. Reservoir Competence of Alphitobius diaperinus (Coleoptera: Tenebrionidae) for Escherichia coli (Eubacteriales: Enterobacteriaceae). Journal of Medical Entomology 1996; 33(6): 983-987.

Morgan $H$. The enteric bacteria. p.610-48. In Dubos RJ, Hirsch JG [ed.] Bacterial and mycotic infections of man. $4^{\text {th }}$ ed. J.B. Lippincott Co., Philadelphia, Pa. 1965; 1025p.

Nascimento MS, Berchieri J r A, Barbosa MD, Zancan FT, Almeida WAF. Comparação de meios de enriquecimento e plaqueamento utilizados na pesquisa de Salmonella em carcaças de frango e fezes de aves. Revista Brasileira de Ciência Avícola 2000; 2(1): 85-91.

Quinn ME, Carter ME, Markey B, Carter GR. Clinical Veterinary Microbiology. London Wolfe Publishing. 1994; 648p.

Steelman D. Beetles threaten profit by damaging house insulation, carrying diseases and reducing growth, fees efficiency. Poultry Digest. 1996; p.22-23.

Watson DW, Guy JS, Stringham SH. Limited transmission of turkey coronavirus in young turkeys by adult Alphitobius Diaperinus (Coleoptera: Tenebrionidae). Journal of Medical Entomology 2000; 37(3): 480-483. 

do Paraná, Brasil 